\title{
When teachers are taught to learn Using team-based learning as a first-time information literacy instructor
}

W Then teaching information literacy as a for-credit standalone course, it's a challenge to find a format that will inspire student engagement. Team-based learning (TBL) is a collaborative learning method that emphasizes student preparation, accountability, and application and provides a framework for students to have more meaningful interactions in the classroom. Students are assigned to teams of five to seven peers on the first day of class and stay in those teams for the duration of the course. Students prepare for class independently by studying assigned materials on a given topic. In class, they work in teams to complete readiness assurance tests and application exercises based on the materials they have studied. The instructor acts as a guide and clarifies concepts as needed. ${ }^{1}$

I first encountered TBL when preparing to teach my first section of UNL 205 at the University of Albany-State University of New York (SUNY). UNL 205 is a one-credit, quarter-long information literacy course that students can take to fulfill a general education requirement. Classes take place in a computer lab setting, where there are seats for up to 23 students. Class sessions take place once a week and are scheduled for two hours. There is no strict requirement for students to take the course at a particular point in their academic career, so each class usually includes a mix of freshmen, sophomores, juniors, and seniors.

When planning to use TBL in a course for the first time, a prospective instructor may notice that much of the related literature is written with the experienced instructor in mind, assuming that the instructor will be converting a previously taught lecture- or discussion-based course to the TBL model. The expectation is that the instructor will be adapting existing course materials and lesson plans as needed.

This might lead one to believe that TBL is only suited to the experienced instructor. However, when preparing to teach UNL 205, I decided as a novice instructor to take up the challenge of using the TBL model and found that not only could I be successful with it, but also that it helped make the sometimes overwhelming process of designing a course for the first time more manageable.

\section{Choosing TBL}

An experienced instructor looking for a change might choose to convert an existing course to TBL as a way to reinvigorate the course or to enhance student engagement and learning. For such an instructor, a main challenge of the conversion is to "design backwards" from the normal routine, which traditionally requires students to complete assignments only after they've heard a lecture or participated in a discussion on that topic. ${ }^{2}$ In TBL, the experienced instructor will need to convert existing course materials and lesson plans to a model in which students learn the information ahead of time rather than through lecture and then spend the bulk of class time building skills through hands-on team activities.

As a first-time instructor, no conversion process was necessary for me. I was able to start fresh with no previous commitment to existing materials, which allowed me to view

Allison Hosier is assistant librarian, information literacy at University of Albany-SUNY, e-mail:ahosier@albany.edu (c) 2012 Allison Hosier 
the course through the TBL lens from the start. The model of preparation, assessment, and application turned out to be a useful template for mapping out the connections between course objectives, assignments, tests, class activities, and projects. This was especially important for me, as someone with little background in pedagogy.

I also found the opportunity to take on a facilitator role in the classroom an attractive one. Though putting so much of the responsibility for learning in the students' hands promised to make the learning environment less predictable than it might have been in a more traditional setting, I felt that it would give me room to develop my teaching skills and build confidence in the classroom by requiring me to become adaptable where needed. I was able to build my course goals and objectives around TBL so that students would be able to learn what they needed to know, even with less instructor input.

\section{Putting TBL into action}

There is a great deal of support for TBL on the University at Albany-SUNY campus and within the Information Literacy Department. The campus Institute for Teaching, Learning, and Academic Leadership (ITLAL) promotes TBL with periodic trainings, including a workshop that was specifically designed to address the needs of UNL 205 instructors, held prior to the Spring 2011 semester. By that time, Trudi Jacobson, an experienced instructor and head of the Information Literacy Department, had successfully converted her sections of UNL 205 to TBL and was encouraging other UNL 205 instructors to consider experimenting with their own sections. ${ }^{3}$

As a first-time instructor, the exceptional support provided by ITLAL and experienced UNL 205 instructors, many of whom were also considering using TBL for the first time, was invaluable. Being able to share concerns and develop strategies as well as observe and become familiar with existing class materials was instrumental to my success.

As an information literacy course, UNL 205 lends itself well to TBL in that units of learn- ing can be based on a specific type of source that students will need to be able to identify, find, evaluate, and use. Fitting this into the TBL model was a matter of creating application exercises that reflected these steps and finding readings that would give the needed background information. Class sessions focusing more on larger information literacy-related issues, such as copyright and privacy, were initially more difficult to map out, but the extra effort did not make using the TBL model for these lessons any less effective.

Being able to use the TBL template in this way helped make the planning stage for the course run more smoothly. Along with the development of the usual course materials, such as a syllabus and assignments, it was also necessary to evaluate and choose effective materials for student preparation, create assessments based on those materials, and plan team activities that would build on concepts from those materials. In addition to these, I also had to decide on a process for choosing teams and create a presentation for the first day of class that would explain the nature of TBL and how it would be used in the course.

This work was time-consuming, as it would be for any instructor, but it helped me create a coherent picture of how different elements of the course built on and supported each other. Worry about the effectiveness of each element was inevitable, but this clarity was helpful.

By the time the course started, all that was left to do was to let everything play out. This particular section of the course consisted of 24 students (one above the norm) with four teams of about six students each. The makeup of the course consisted of more male students than female students, and most of the students were juniors and seniors. The students' grades for the course consisted of about 40 percent for team work and 60 percent for individual work. None of the students had experience with TBL prior to the course.

The students took the TBL model in stride and the level of engagement was reasonably high throughout. Any initial confusion about my role in the course was overcome and the students worked together willingly on team 
activities. There were a few moments where the less predictable nature of TBL came into play, as with a lesson where teams were asked to locate a book on the shelf in the library. Though an explanation of call numbers was included in the preparation materials for that day, some students were still unclear about how books in a library were organized. In this case, teams either negotiated a process of trial and error or students with more experience filled in the missing knowledge for their teammates. Afterward, I clarified further with a brief, improvised lecture. Allowing students to first attempt to solve the problem themselves and then asserting my expertise proved to be a positive and enlightening experience.

More often than not, activities ran smoothly. Many activities were inspired by ideas that had been used by other UNL 205 instructors in their TBL and non-TBL classrooms, as well as exercises I had read about in books about active learning. One activity that received a positive response from the students required them to sort scraps of paper with different sources written on them (such as a diary or a newspaper article) into categories according to whether or not the teams thought the source was primary. All of the teams were given the same set of sources to work from, and after making their decisions, they were asked to write down what they had decided for a particular source on a marker board. I asked all of the teams to hold up their marker boards at the same time so none had an opportunity to change their answer.

There was often disagreement between teams as to which category a source belonged to, and I asked the teams to explain why they'd chosen the way they had. The ensuing discussion revealed the importance of context when deciding whether a source is primary.

When asked for feedback about the TBL process, first as part of a midterm evaluation provided by ITLAL and then as part of a followup class discussion, students gave open and honest feedback about what was working for them and what was not. Not surprisingly, the students showed the most unhappiness with the assessments, though they felt that a fair compromise for future sections of the course would be to drop the lowest grade on these assessments. They also provided helpful feedback on the team activities, sharing which ones had interested them the most and criticizing any that gave the feeling of simply filling out a worksheet.

In the course evaluations, which were generally positive, only a few students included comments about TBL. If students criticized the TBL model, it was more to express that they felt it was unnecessary rather than because they felt it had interfered with their learning. This criticism was balanced by students who felt that TBL had enhanced their course experience.

\section{Further experience}

After using TBL in the Spring 2011 semester, I used it in three more sections of UNL 205 in the Fall 2011 semester and two more sections in the Spring 2012 semester. My experience has been such that I have never considered teaching the course a different way, even as I continue to tweak the approach.

A particular area in which my teaching has become more refined over time has been in the design of team activities, based on student feedback and a better understanding of the TBL tenet that activities should require teams to work on the same problem, make a specific choice, and report their choice simultaneously. ${ }^{4}$ Before I asked teams to find a book on a shelf in the library and then answer a series of open-ended questions that would help them evaluate the book, but now I show them the records for a series of sources on a given research topic and ask the teams to give those sources a grade based on the information in the record. Students have an easier time articulating why they gave a source a good grade or a bad grade than describing why it is a good source or a bad source off of the top of their heads. This more open-ended approach is saved for the second stage of the activity, which requires the teams to locate a book in the library that they feel is a better source for the research topic than what I showed them. They then present what they found to the other teams, who evaluate their choice. This inspires 
an atmosphere of friendly competition and in many cases has promoted lively discussion.

When TBL is at its best, it inspires meaningful contribution that can be enlightening not only for the students but also for the instructor. Lively interactions within teams and between teams in UNL 205 are not uncommon, and the atmosphere in the classroom is often positive and energetic. This has been true for me even in classes with only 10 to 12 students.

Using TBL on a continuing basis has also revealed that its success is dependent on a number of factors, of which the experience of the instructor is only one. Class size, team size, and class makeup also play a role, and, while the experienced instructor may be more adept at dealing with the effects of these differences, any instructor's skills will be honed through use of the TBL model.

\section{Conclusion}

While much of the literature on TBL is written with the experienced instructor in mind, I found that it is more than possible for the first-time instructor to have success using the model. In the future, my hope is to continue working with and promoting TBL while adapting the model to an online version of the UNL 205 course.

\section{Notes}

1. Jim Sibley and Sophie Spiridonoff, "Introduction to Team-Based Learning Handout," Team-Based Learning Collaborative, accessed September 12, 2012, www.teambasedlearning.org/starting.

2. Larry K. Michaelsen, "Getting Started with Team-Based Learning." In Team-Based Learning: A Transformative Use of Small Groups in College Teaching, edited by Larry K. Michaelsen, Arletta Bauman Knight, and L. Dee Fink (Sterling, VA: Stylus Publishing, 2004): 27-50.

3. Trudi Jacobson, "Team-Based Learning in an Information Literacy Course," Communications in Information Literacy 5, no. 2 (2012)

4. Michaelsen, In Team-Based Learning, 51-72. n

\section{We play nice together}

Now there are even more reasons for ILLiad users to adopt Ares for e-reserves and Aeon for special collections management.

Save staff time with the synergy of workflow addons that work across all three Atlas products.

Improve research services by seamlessly processing ILL requests for special collections materials through ILLiad and Aeon in tandem.
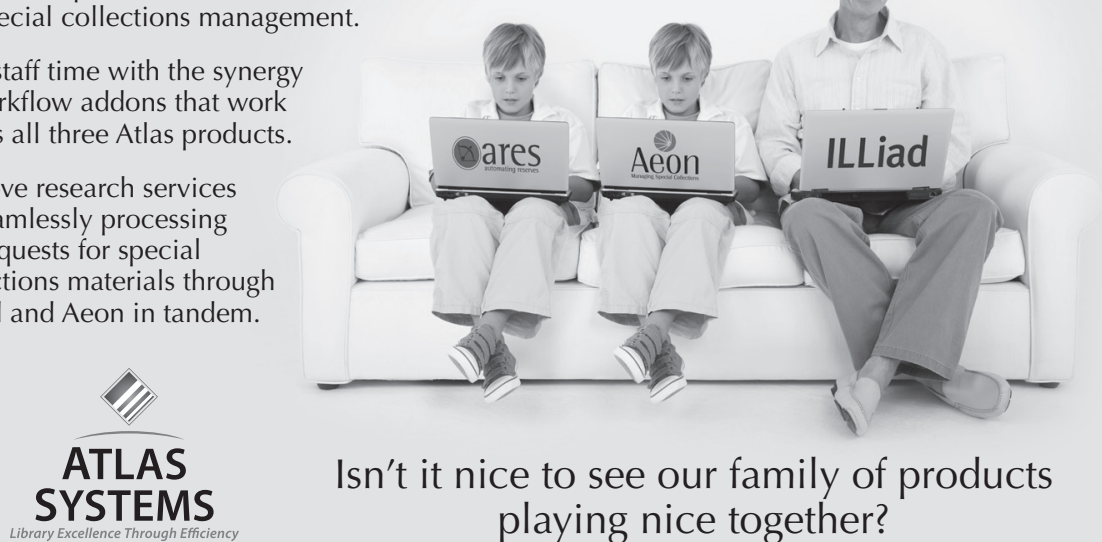

Isn't it nice to see our family of products playing nice together?

Visit www.atlas-sys.com to sign up for a demo. 